\title{
Managing patients with rheumatic conditions during the covid-19 pandemic
}

\author{
Roberto Caporali rheumatologist, Ennio Giulio Favalli rheumatologist \\ Reumatologia Clinica, ASST PINI-CTO, 20122 Milan, Italy
}

Chronic rheumatic conditions are other long term conditions that could be negatively affected by the covid-19 pandemic. $^{1}$

Rheumatic diseases are among the most disabling diseases in the world, ${ }^{2}$ and affected patients typically need to be strictly followed to ensure a good quality of life and to maintain control of disease activity. Moreover, patients with autoimmune chronic arthritis (namely rheumatoid arthritis and seronegative spondyloarthritis) are usually treated with immunosuppressant drugs, which might impair their immune response and confer an increased risk of infection.

Yet recommendations on how to manage patients with autoimmune diseases, how to deal with anti-cytokine drugs used by about $20 \%$ of these patients, and how to keep disease activity under strict control in the context of covid-19 are all still lacking. The mainstay for optimal chronic arthritis management is the treat-to-target strategy, which involves frequent clinical assessment of disease activity. ${ }^{3}$ How this could be performed in the future needs rapid evaluation and response. Early diagnosis and treatment are the main prognostic factors for achieving clinical remission as well as halting radiographic progression. "Early arthritis clinics" have been set up around the world to shorten the delay between symptom onset and diagnosis (and treatment). But these services are currently not running properly, with all our efforts being focused on patients with covid-19.

Rheumatologists should start thinking about the future of their patients and start organising new ways to follow their patients to avoid a major backwards step, losing all of the fantastic clinical results obtained over the past 15 years.

Competing interests: None declared.

Extance A. Covid-19 and long term conditions: what if you have cancer, diabetes, or chronic kidney disease?BMJ 2020;368:m1174. 10.1136/bmj.m1174 32213482

2 Fayaz A, Croft P, Langford RM, Donaldson LJ, Jones GT. Prevalence of chronic pain in the UK: a systematic review and meta-analysis of population studies. BMJ Open 2016:6:e010364. 10.1136/bmjopen-2015-010364 27324708

3 Smolen JS. Treat to target in rheumatology: a historical account on occasion of the 10th anniversary. Rheum Dis Clin North Am 2019;45:477-85. https://www.rheumatic.theclinics. com/article/S0889-857X(19)30055-9/fulltext31564291

4 Burgers LE, Raza K, van der Helm-van Mil AH. Window of opportunity in rheumatoid arthritis - definitions and supporting evidence: from old to new perspectives. RMD Open 2019;5:e000870. 10.1136/rmdopen-2018-000870 31168406

Published by the BMJ Publishing Group Limited. For permission to use (where not already granted under a licence) please go to http://group.bmj.com/group/rights-licensing/ permissions 